\title{
OS NEGROS AMERICANOS EM UM CATIVO APAIXONADO, DE JEAN GENET (DO CLICHÊ SOBRE O NEGRO A SUA IMAGEM EM MOVIMENTO)'
}

\author{
Patrice Bougon \\ (CERACC - Université de Paris III)
}

Antes de abordar o tema dos Negros americanos no último livro de Genet, publicado poucas semanas depois de sua morte, em 15 de abril de 1986, é importante relembrar o contexto histórico e os aspectos singulares que deram origem ao movimento dos Black Panthers.

\section{Contexto histórico e pesquisa formal}

A maior democracia do mundo foi fundada sobre a segregação racial. Até 1964, os Negros não tinham o direito de pegar o mesmo ônibus que os Brancos nem podiam ir aos mesmos restaurantes. Sem nenhum problema, a maioria dos políticos americanos proferia discursos claramente racistas, o que hoje seria impensável. Nos anos cinquenta, movimentos negros começaram a lutar por seus direitos civis; nos anos sessenta, em razão

${ }^{1}$ Nas citações de Um cativo apaixonado, foi utilizada a tradução realizada por Cláudia Fares, publicada no Brasil pela Editora Arx, em 2003, indicada nas referências bibliográficas (N.doT.). 
dos discursos carismáticos do pastor negro Martin Luther King e, ainda mais veementes, os de Malcolm X, e também devido aos efeitos da política de abertura de John Kennedy, a situação evoluiu positivamente, mas à custa do assassinato desses três homens. Muitos outros negros também foram mortos durante manifestações e nas prisões. A partir de $1970^{2}$, o caso George Jackson instigou Genet a redigir diversos textos militantes. Neste contexto político, bastante tenso, os Black Panthers escolheram a luta armada para fundar, de maneira totalmente utópica, uma nação negra nos Estados Unidos. Sendo o direito de porte de armas garantido a todo cidadão pela constituição americana, os militantes formaram uma pequena armada, principalmente para se defenderem contra os assassinatos cometidos legalmente pelos policiais. Músicos, atores, escritores americanos militaram a favor do movimento, incluindo James Brown, Jane Fonda, Jean Seberg, Dalton Trumbo. Um movimento de revolta que, diante de jornalistas, tratava Nixon e os policiais de "pigs" que deviam ser abatidos só poderia atrair Genet.

Para situar a questão da relação de Genet com os negros americanos no período de 1968-1972, durante muito tempo, pesquisei se, na época, algum intelectual, conhecido na Europa, havia falado sobre essa questão. Imaginava que Hannah Arendt ${ }^{3}$, judia que havia fugido da Alemanha nazista, intelectual de coragem exemplar envolvida em muitas batalhas, tendo construído toda a sua carreira em universidades americanas, autora de ensaios importantes sobre política, provavelmente tivesse publicado textos essenciais sobre um tipo de descriminação de que certamente havia sido testemunha. Ora, eis o que ela escreveu, em 22 de novembro de 1970, a Mary Mac Carthy, uma amiga próxima, a respeito de uma crítica que esta havia feito acerca de um documentário sobre os Black Panthers: "Obrigada pela descrição do filme dos Panthers. Evidentemente, é assim mesmo que eles se comportam: loucos, viajando por causa das drogas e da retórica" (ARENDT, 2009, p. 375).

Opinião, ou melhor, julgamento surpreendente, pois é resultado, em parte, de um clichê (ou estereótipo) que Genet, esse escritor livre de todo poder institucional, desfaz em Um cativo apaixonado. Esse livro, composto de duas partes, intituladas simplesmente Lembranças I e Lembranças II, é dedicado, sobretudo, aos Palestinos, com quem viveu por dois anos, mas também, em menor medida, aos Black Panthers, que

2 Esses textos foram reunidos por Albert Dichy, em L'Ennemi déclaré, textes et entretiens [1964-1985]. George Jackson, preso durante onze anos por ter roubado menos de setenta dólares, foi morto na prisão por um guarda.

${ }^{3}$ Arendt chegou aos Estados Unidos em 1948. 
ele acompanhou por dois meses, ministrando conferências em diversas universidades americanas. Apesar da brevidade da relação, deve-se ter em mente que são principalmente os Black Panthers que desencadeiam o retorno de Genet à escrita, pois, desde a publicação de Paravents, em 1962, ele não havia publicado praticamente nada. Os dois curtos textos - Ce qui est resté d'un Rembrandt e L'étrange mot d' - publicados em Tel quel, revista dirigida por Philippe Sollers, em 1967, eram fragmentos de projetos antigos abandonados. Em outras palavras, traços de dois futuros livros, mas também de um duplo fracasso que deixava desmunidos tanto o autor quanto o leitor.

Em 1986, Um cativo apaixonado retoma, de um modo mais organizado e desenvolvido, o material de alguns artigos jornalísticos de Genet publicados principalmente em L'Humanité. Atingindo outro nível, esse volume de quinhentas páginas possibilita, a partir de uma perspectiva diferente 4 , um trabalho de repetição e de variação, impossível de se realizar em um curto artigo de poucas páginas. Se Um cativo apaixonado é um relato autobiográfico que toma o partido dos Black Panthers, a forma de seu engajamento é ímpar, pois tal como com os palestinos, Genet mostra-se bastante crítico em relação ao direcionamento do movimento, que foi rapidamente desvirtuado pelo dinheiro, as drogas, a rivalidade dos grupos e das ideologias, mais ou menos islâmicas, ou seja, contrárias, para Genet, ao espírito de toda revolta, visto que um crente não pode discutir os preceitos da fé.

Podemos nos perguntar por que Genet se interessou por este movimento, e não pelo Vietnã, ou por outros movimentos revolucionários, ou por Cuba, que seduziu diversos intelectuais nos anos sessenta (Sartre, Leiris, Guyotat, Maurice Nadeau, Régis Debray e outros menos renomados). Para Genet, a América é mais que um país; é o símbolo do imperialismo dos Brancos no mundo e é também o principal apoiador de Israel, enfim é o exemplo da democracia mais poderosa do mundo que tem a particularidade de ser fundada tanto sobre um genocídio - o dos Índios - quanto sobre a escravidão dos Negros. Após os acontecimentos de maio de 1968, em Paris, Genet descobre (ilegalmente) uma América onde a violência policial, judiciária e carcerária reinava sem problema, como testemunham os escritos de alguns Panthers, como A l'affût (1972), de Bobby Seale, Sortir du Ghetto (1997), de Elaine Brown e, principalmente, Autobiographie (1975), de Angela Davis. Esta última, com um doutorado em filosofia, sob a orientação de Herbert Marcuse, propôs a análise mais

\footnotetext{
${ }^{4}$ Seria interessante comparar a abordagem de Genet com a de Nietzsche e Péguy.
} 
rigorosa da situação. Importante lembrar que Angela Davis foi presa pela polícia e corria o risco de ser condenada à morte em 1970, tendo passado dezesseis meses na prisão, o que lhe permitiu descrever as condições de vida numa prisão americana dignas da Idade Média ou... de um romance de Jean Genet!

Essa violência legal é uma das razões da raiva de Genet; sentimento que foi essencial para provocar, em 1968, a retomada do seu movimento de escritura quando parecia que havia abandonado essa prática. A raiva foi ainda mais intensa e seus efeitos mais duradouros, em 1982, quandoocorreu o massacre de Chatila, do qual ele foi testemunha e que deu origem a Quatre heures à Chatila 5 e, em seguida, à redação de Um cativo apaixonado. $\mathrm{O}$ engajamento político de Genet pela causa dos Black Panthers também se sustenta devido à admiração por um estilo de vida, uma maneira de falar, movimentar-se, vestir-se, ser comunidade. Sobretudo, Genet se diverte ao apresentar-se ao leitor como "filho adotivo" de um dos líderes dos Black Panthers. Mais adiante, retomarei este ponto. Acima de tudo, devemos insistir no fato de que a relação de Genet com a América é a de um poeta que imagina perspectivas singulares, uma sintaxe narrativa, uma retórica, para abordar a realidade política, interrogando-se constantemente sobre a sua relação com a verdade histórica. Para Genet, trata-se de inventar uma forma de narrativa dos acontecimentos históricos conhecidos, evitando, porém, todo clichê jornalístico ou ideológico. Sua abordagem assemelhase a um trabalho de filólogo, filósofo, poeta que reflete sobre os termos mais comuns ("Brancos", "Negros", "imagens", "palavras") que pontuam o seu testemunho.

O título deste ensaio poderia ser "A América em preto e branco", para fazer jus à ambiguidade de cada uma das palavras do texto de Genet. Em consonância com o seu trabalho poético em Um cativo apaixonado, essa expressão suscita o duplo sentido de cada termo que a constitui. A oposição dessas duas cores é também a de duas metonímias que remetem a duas comunidades, a dos "Negros" e a dos "Brancos". Ora, a identidade desses dois inimigos é, para Genet, um "clichê" desfeito por ele para mostrar como essa relação conflituosa explícita oculta outra, ainda mais ambivalente. Em meu título, o termo "clichê" é também uma metáfora que remete à fotografia, mencionada várias vezes pelo narrador para lembrar como seu aparente realismo é, de fato, uma ilusão que somente a escrita literária pode tornar realidade. Quanto ao termo "imagem", também se refere a mais de uma coisa. Inicialmente, à representação pública,

5 Texto incluído em L'Ennemi déclaré (DICHY, 1991). 
política, ideológica, mas também à metáfora presente na frase um tanto enigmática da epígrafe do seu livro: "Resguardar todas as imagens da linguagem e utilizá-las, pois elas estão no deserto, onde é preciso ir buscálas". Observemos que o termo "imagem" é constantemente interrogado em Um cativo apaixonado, mas também em duas de suas peças de teatro: Le Balcon (1956) e Les Paravents (1962), pois é essencial para Genet criticar e destruir, para não dizer "desconstruir", esta noção (imagem) que funda e estrutura a prática de todo poder.

Entre as diversas sequências que evocam a América em Um cativo apaixonado, selecionei as que sugerem, em toda a sua complexidade, o entrecruzamento dos três temas seguintes: o contraste entre a página branca e a escrita negra, o estatuto da imagem e da retórica nos Black Panthers e, por fim, a temporalidade da história dos Negros.

\section{O clichê na relação entre a página branca e os caracteres negros}

Geralmente, a crítica cita a primeira página de Um cativo apaixonado propondo uma paráfrase que me parece insuficiente tanto em termos de significado quanto pelo fato de que os comentários normalmente esquecem que essa primeira página é apenas a primeira ocorrência de uma série que eu gostaria de analisar para mostrar como seu significado usual se desfaz:

A página que no início era branca, agora está cruzada de alto a baixo por minúsculos sinais negros, as letras, as palavras, as vírgulas, os pontos de exclamação, e é graças a eles que se diz que essa página é legível. Contudo, há uma espécie de inquietação no espírito, há essa vontade de vomitar muito próxima da náusea, há uma oscilação que me faz hesitar em escrever... seria a realidade esta totalidade de sinais negros? O branco, aqui, é um artifício que substitui a translucidez do pergaminho, o ocre marcado dos tabletes de argila, mas este ocre em relevo, como a translucidez e o branco, talvez tenha uma realidade mais forte que os sinais que o desfiguram. A revolução palestina foi escrita sobre o nada, um artifício sobre o nada. A página em branco e cada minúsculo espaço de papel branco que aparece entre duas palavras seriam mais reais que os sinais negros?

(...)

Quando afirmei que os Negros eram os caracteres sobre a folha branca da América, uma imagem superficial, a realidade estava sobretudo onde eu nunca saberia precisar exatamente, ali onde se representa o drama amoroso entre dois americanos de cores diferentes. (GENET, 2003, p. 9-10) ${ }^{6}$

\footnotetext{
${ }^{6}$ Aqui, como em outras partes, as palavras são sublinhadas por mim.
} 
Nessa passagem inaugural, a crítica, muitas vezes, limitou-se a louvar uma dupla metáfora: o Branco como papel, o Negro como palavra. Porém, em Genet, o que é dado a ler, frequentemente, encobre outra coisa. Praticamente, não se evidenciou queo sistema de escrita, que nos éfamiliar, o do papel e da tinta, inscreve-se em uma genealogia das técnicas que permite a Genet brincar com a oposição entre Brancos e Negros, suscitando outros pares metafóricos relacionados às técnicas de inscrição que, na economia textual de Um cativo apaixonado, são sobredeterminadas: o pergaminho e a sucessão, logo a superposição das inscrições em palimpsesto, mas também o oco e o relevo das tábuas de argila. Por meio dessas duas técnicas de inscrição, o que é visível esconde outra coisa, seja nas camadas do palimpsesto, seja na sombra do relevo, de modo que essa primeira página possui o estatuto de alegoria da escrita, mas também da leitura, para usar o título de um ensaio de Paul de Man (1989) ${ }^{7}$. A tábua de argila é uma metáfora que pretende não somente realçar o contraste entre luz e sombra, presente ao longo da narrativa, mas também remeter aos tempos bíblicos evocados em algumas sequências sobre os Palestinos e, por fim, de modo mais oblíquo, aos Negros americanos, na medida em que David Hilliard, um dos dirigentes dos Black Panthers, é descrito como um "patriarca" do Antigo Testamento. Mais adiante, retornarei a essa questão.

\section{Uma dupla temporalidade}

Uma das minhas hipóteses de leitura é a de que a histocidade dos sistemas de escrita que abre Um cativo apaixonado, sujeita a múltiplas variações, programa uma ideia de tempo que se opõe ao clichê dos tempos linear, jornalístico e até mesmo histórico.

Um cativo apaixonado, por meio das "lembranças" do autor, possibilita uma ampla reflexão sobre a histocidade das nações (Israel, Estados Unidos, Palestina), mas também do Negro. A representação do tempo que estrutura a escrita de Um cativo apaixonado revela-se não apenas linear (determinada pela sequência dos acontecimentos sucessivos da História), mas estratificada como um palimpsesto (um acontecimento

${ }^{7}$ Genet escreve nesta primeira página: “Ler entre as linhas é uma arte estabilizada, ler entre as palavras é uma arte vertiginosa” (2003, p. 9).

${ }^{8}$ Termo que convém interrogar, apesar de sua aparente simplicidade. Sem dúvida, deve ser entendido no sentido etimológico: o latim "souvenir": "apresentar-se ao espírito". Mais adiante, retomarei esse ponto. 
reativa outra inscrição na memória do sujeito da escritura). O que Freud nos ensinou sobre a memória, em seu estudo "Nota sobre o bloco mágico" (1929)9 , adquire, em Um cativo apaixonado, um aspecto singular, sobredeterminado pela metáfora do pergaminho e do palimpsesto, presente na primeira página. Além disso, Freud é citado, ao menos duas vezes, na série de digressions que pontuam a narrativa.

Na citação anterior, podemos observar vários traços essenciais do estilo de Genet: a multiplicação das metáforas, todas insuficientes para dizer a realidade, mas também um movimento reflexivo que rasura, em parte, o que foi escrito: "uma imagem superficial". A relevância dessa sequência excede o que à primeira vista parece ser uma simples reflexão sobre os limites da representação literária em termos de realidade, uma vez que o termo "desfigura" amplia violentamente o julgamento de incompletude.

Enfim, é surpreendente que a oposição entre Brancos e Negros seja apresentada como uma relação afetiva: "ali onde se representa o drama amoroso entre dois Americanos de cores diferentes". Esse paradoxo é a última versão da relação ambígua, e até mesmo ambivalente, que a obra de Genet mantém com o inimigo. A admiração do vadio pelo policial em Querelle (1947), do juiz pelo criminoso em Le Balcon (1956), do colonizado pelo colonizador, do revoltado pela ordem estabelecida em Les Paravents (1962). Essas obras põem em cena como o movimento de revolta pode ser alterado por uma simples batalha de lugares e pela imitação do modelo dos antigos mestres.

\section{Mallarmé e Genet}

Um último aspecto relevante desta página inicial refere-se à alusão a Mallarmé, poeta cuja obra assombra Um cativo apaixonado, e mesmo toda a obra de Genet. A companhia de Sartre, que, desde 1948, se dedicava a um ensaio sobre Mallarmé (do qual apenas uma parte seria publicada), sem dúvida, teve impacto sobre Genet, mesmo porque Saint Genet (1952) está repleto de referências a Mallarmé (assim como Glass de Derrida). Em 1954, Genet publicou, em Les temps modernes, Fragments, texto em que a estrutura da página apresenta três, quatro colunas, com o uso de fontes diferentes, em referência à estrutura da página de Um lance de dados jamais

\footnotetext{
${ }^{9}$ Refiro-me ao famoso estudo que Derrida dedicou a este texto em "Freud et la scène de l'écriture", L'Ecriture et la différence (1979, p.293-340).
} 
abolirá o acaso. Entretanto, como Freud, Genet desloca as proposições do poeta do século XIX, em Divagations ou Crayonné au théâtre, que foram, em seu tempo, a expressão de um pensamento inédito sobre a literatura, mas que depois de Blanchot, de poetas como Du Bouchet e de críticos da modernidade (Barthes, Sollers, Foucault, Derrida), acabaram por tornarse um clichê.

Oencontrocomos Black Panthers foi uma sorte para Genet, poisprovocou a retomada da escrita, primeiro, sob a forma de artigos ditos de circunstância, entre 1968 e 1971, que foram reunidos em L'Ennemi déclaré. Sabemos, desde Mallarmé, autor de Versos de circunstância, e mais recentemente com Michel Deguy $^{10}$, o quanto a noção de circunstância serve para avaliar positivamente. Em Um cativo apaixonado, essa noção é enriquecida por múltiplas variações desta, sobredeterminada, de "acaso" [hasard]. Com efeito, "hazard" é uma palavra árabe, que significa "dado", sendo que uma cena de "jogo de dados" é mencionada diversas vezes nessa longa narrativa. Observamos, enfim, que o acaso, em outras palavras, o "dado", aponta para Mallarmé, autor de Um lance de dados jamais abolirá o acaso.

Este pensamento descontínuo e repetitivo, acerca do acaso e da circunstância, interroga a origem da escrita política e sua motivação plural. Tal questionamento desafia o gênero estereotipado da literatura engajada, pois sua narrativa mantém uma relação estreita com o pensamento poético cuja figura emblemática é Mallarmé. Ainda em relação a esse ponto, destacamos um verso de Le tombeau de Verlaine, "um riacho raso que calunia”, citado sem que o nome do autor, Mallarmé, seja mencionado. Como dito, o fantasma de Mallarmé assombra esse livro que também reflete sobre a morte do autor e o sujeito da escrita teorizados por Barthes e Derrida. Em Um cativo apaixonado, o estereótipo é, no entanto, completamente alterado, pelo fato de que o "dado" de Mallarmé, isto é, o "acaso/azar" ["hasard/hazard"], é tomado ao pé da letra (árabe), se posso dizer, ou, se preferirmos, no sentido dito próprio. A prática, comum em Genet, da silepse (figura que consiste em utilizar uma palavra tanto no sentido próprio quanto no sentido figurado) é pensada em relação ao fato de que a oposição do papel branco e dos caracteres negros da página abre, ao contrário das Divagations de Mallarmé, para uma reflexão política, no caso de Genet, acerca dos Black Panthers. Finalmente, salientamos que Um cativo apaixonado homenageia Mallarmé, quando lemos: "O autor, como aqueles dos quais ele fala, também está morto” (2003, p. 436), que

${ }^{10}$ Toda a sua obra é atravessada por um pensamento sobre esse conceito, como podemos ver em "Circonstances", em Grand Cahier Michel Deguy (MOUSSARON, 2007, p.158-201). 
lembra: "A obra pura implica a desaparição elocutória do poeta, que cede a iniciativa às palavras, pelo choque de sua desigualdade mobilizadas" (MALLARMÉ, 1976, p. 248).

O engajamento, a temporalidade, a poesia são noções, como acabamos de ver, discutidas na narrativa de Genet, desfazendo os clichês e seus efeitos de crença. Podemos, agora, continuar nossa leitura para tentar entender a difícil articulação, proposta por Genet, entre poesia, revolta e beleza.

\section{A revolta poética ou a beleza do político}

Em Um cativo apaixonado e em outros textos, Genet opõe a "revolta", movimento sem fim, à "revolução", entendida como simples inversão cuja motivação essencial é tomar o lugar de quem tem o poder sem pensar em transformar plenamente a sua estrutura. Minha hipótese de leitura é a de que há uma analogia implícita em Genet entrea revolta política permanente, ilimitada e a exigência da escrita política que ele se propõe a inventar em cada página de Um cativo apaixonado, uma retórica capaz de dar a ver, de forma inédita, o que o leitor de jornal conhece de um modo estereotipado ou ideológico. Para Genet, a poeticidade de sua narrativa é adequada a seu objeto, na medida em que a revolta dos Black Panthers, embora bem real, registrada pelos jornalistas e pelos estudos dos historiadores, participa da ilusão mimética e da metáfora: "seu movimento, mais revolta poética e diversão do que vontade de uma mudança radical, era um sonho flutuando sobre a atividade dos Brancos" (GENET, 2003, p. 248).

O que é a escrita poética senão o que inventa determinado uso de palavras, produzindo aproximações inéditas e revelando, de uma maneira nova, a realidade, aqui política, de forma a evitar todo estereótipo? $\mathrm{Na}$ citação, o engajamento dos Black Panthers e a relação entre amigo e inimigo são apresentados em contradição com todo clichê, na medida em que os termos utilizados por Genet - "poética", "jogo" e "sonho" - desfazem totalmente a seriedade ostentatória do combate político.

Esse vínculo surpreendente entre combate político e poesia também pode ser visto em uma sequência que é uma dentre as inúmeras variações da primeira página, cuja estrutura já analisei e da qual, agora, verificaremos o valor programático:

As palavras negras na página branca americana são às vezes rasuradas, apagadas. As mais belas desaparecem, mas são elas - as desaparecidas - que formam o poema - ou antes o poema do poema. Se os brancos são a página, 
os negros são o escrito que diz um sentido - não da página, ou não somente da página. A profusão de branco permanece sendo o suporte da escritura e é sua margem, mas o poema é composto pelos negros ausentes e anônimos. Sua reunião constitui o poema cujo sentido me escapa, mas não sua realidade (GENET, 2003, p. 311).

A morte torna-se aqui um tema ligado à prática da escritura, porém, mais uma vez, Genet evita o clichê, na medida em que os mortos jamais são eliminados. De certo modo, como todo elemento passado da História, eles retornam, pois a temporalidade, como já indiquei, estrutura-se em palimpsesto:

Da Grécia aos Panteras, a história é feita da necessidade de extrair de si - se se quiser, de delegar ao futuro - imagens fabulosas, que sobreviverão por muito, muito tempo após a morte. (GENET, 2003, p. 429)

O que também altera a alegada seriedade do engajamento político dos Black Panthers é seu gosto pela teatralidade, que tem o efeito de tornar visível essa dimensão indispensável de todo poder, e que, no teatro, foi posta em cena por Le Balcon:

Emblemático: cabeleiras afro, prendedores de cabelo de ferro, apertos de mão pertenciam também a outros movimentos negros, mais voltados para a África - uma África imaginária onde o Islã se confundia com o animismo. Os Panteras não recusaram esses símbolos, mas acrescentaram "All Power to the People", a Pantera Negra sobre fundo azul, o casaco de couro, o gorro, mas sobretudo as armas expostas, ostensivamente visíveis (GENET, 2003, p. 62).

Genet ironizava as contradições ideológicas de seus amigos submetidos a uma religião híbrida e bastante vaga, mas também em uma relação totalmente fictícia com a África, visto que os descendentes de escravos jamais tiveram qualquer ligação com esse país. Podemos lembrar como o boxeador americano Cassus Clay tornou-se Muhammad Ali, crente muçulmano, tornando visível a sua ligação fantasmática com a África. O termo "emblema", utilizado por Genet, indica que os Black Panthers, como os poetas, transformam os elementos de seus aspectos físicos e das coisas do mundo por meio do uso de metáforas. Há um deslocamento do sentido das coisas e dos signos. A cabeleira ou a boina tornam-se outra coisa, além de um simples penteado ou um chapéu, adquirindo um valor simbólico único. Genet dá exemplo de uma mudança de valor, ou conotação, das palavras. O que era negativo para os racistas, torna-se positivo para os Black Panthers: 
Atuando através de imagens, despertando entusiasmos, eles impunham o "Black is Beautiful", que se impunha por si mesmo aos tiras negros, e até mesmo aos Uncle Toms (GENET, 2013, p. 62).

\title{
Tanto o sentido das palavras quanto o sentido das coisas, para os Panthers, são analisados por Genet:
}

\begin{abstract}
Você vem conosco?
Ele [David Hilliard] sorriu um pouco, disse não e fez um comentário que me pareceu enigmático:

- Lá ainda há muitas árvores.

(...)

Assim, ainda hoje, para um Negro de apenas trinta anos, uma árvore não é o que ela é para um Branco, uma festa de folhagens, de pássaros, de ninhos, de corações gravados e de nomes entrelaçados: é um patíbulo. A visão de uma árvore trazendo de volta um terror nem tão antigo secava a boca, tornava quase inúteis as cordas vocais: passando a corda sobre a viga mestra, um Branco segurava a corda, isto foi o que o Negro que iam linchar viu primeiro. O que nos separa dos Negros de hoje não é tanto a cor da pele ou a forma dos cabelos, mas este psiquismo atravessado por pavores que jamais conheceremos, salvo quando um Negro, de uma maneira ao mesmo tempo humorística e secreta, pronuncia uma frase que nos parece enigmática (GENET, 2003, p. 68-69).
\end{abstract}

Pelos termos “trazendo”, "pavor”, Genet dá conta não somente de uma temporalidade linear, na qual o passado seria ultrapassado, mas de uma temporalidade espectral.

Para finalizar, gostaria de citar uma passagem irônica que mostra como, para Genet, essa comunidade política também evoca uma metáfora da mãe que ele não teve:

Mais tarde eles [os Panteras] rirão quando eu disser a David, que quer, de toda maneira, chamar um médico por causa da minha gripe:

- Você é uma mãe para mim.

A primeira vez que vi David Hilliard foi após uma conferência para os estudantes da Universidade de Connecticut. Depois da conferência, os estudantes negros nos convidaram para ir a seu chalé no campus. Cheguei depois de David. Ele estava sentado e falava no meio dos estudantes, rapazes e moças negros. A muda interrogação de todos os rostos negros me impressionou. Os rostos de filhos e filhas de burgueses negros escutando um antigo caminhoneiro que era um pouco mais velho que eles. Ele era o patriarca falando à sua descendência e lhe explicando as razões da luta e o sentido da tática. Essas relações eram políticas e, contudo, não era apenas o interesse político que congregava essa coesão, mas um muito sutil e muito forte erotismo. Tão forte, e ao mesmo tempo tão evidente e discreto, que jamais tive desejo por nenhum deles: eu era só desejo por esse grupo e meu desejo era satisfeito pelo fato de o grupo existir. 
O que significava minha presença branca e rosa no meio deles? Ainda o seguinte: durante dois meses fui o filho de David. Meu pai era negro e tinha trinta anos a menos que eu. (GENET, 2003, p. 369-370)

O nome "David" e a palavra "patriarca" apontam para o Antigo Testamento. Ora, Genet, em que a obra, ainda que de modo sacrílego, dá um testemunho da fé católica, apresenta-se, apesar de órfão, como filho de um negro, cuja organização deseja, em parte, submeter-se aos dogmas do Islã: três religiões ${ }^{11}$ são, portanto, sobrepostas na figura de uma personagem, como no palimpsesto evocado no início da narrativa. Esta sequência é também uma oportunidade de jogar mais uma vez com a temporalidade e, neste caso, inverter a ordem cronológica da filiação. Enfim, o fato de Genet tornar-se filho de David Hilliard é uma maneira de interrogar seu nome próprio herdado de um Negro e, assim, colocar em questão a oposição entre Negros e Brancos, tanto mais que recentes pesquisas biográficas ${ }^{12}$ revelaram o suposto nome de seu pai: Frédéric Blanc. Que Genet soubesse disso ou não, questão de acaso em suma, o leitor pode, por sua vez, incorporar esse biografema para calcular a dimensão significante do trabalho do espaçamento que Genet levou em consideração durante a composição de sua narrativa. O nome do pai Blanc - é apagado da vida de Genet, mas torna-se legível, por assim dizer, entre as palavras, em suas mediações, próximo da morte, sobre a brancura do papel e sua relação com a escritura.

Tradução: Milena Magalhães

\section{REFERÊNCIAS BIBLIOGRÁFICAS}

ARENDT, Hannah. Correspondance. 1949-1975, Hannah Arendt et Mary Mac Carthy, Paris, Editions Stock, 2009.

BOUGON, Patrice. « Renaissance de Genet : suppléments biographiques », Spirale (org. Véronique Lane), Montréal, $n^{\circ}$. 240, 2012.

. «Politique, ironie, et religion dans Un Captifamoureux», in: ALAZET, B. ; DAMBRE,

M. Jean Genet. Rituels de l'exhibition. Dijon: Editions universitaires de Dijon, 2009.

"Sobre esta questão, gostaria de remeter ao meu estudo: « Politique, ironie, et religion dans Un Captif amoureux » (dans ALAZET; DAMBRE, 2009, p. 81-90).

${ }_{12}$ Em Jean Genet. Matricule 192.102. Chronique des années 1910-1944 (DICHY ; FOUCHÉ, 2010). Quanto aos problemas de método colocados por este livro, remeto ao meu artigo "Renaissances de Genet : suppléments biographiques ", Spirale, $\mathrm{N}^{\circ} 240$ (BOUGON, 2012, p. 41-43). 
BROWN, Elaine. À l'Affût. Paris: Gallimard (collection Témoins),1972. Sortir du Ghetto. Paris: Editions Nil, 1997.

DAVIS, Angela. Autobiographie. Paris: Albin Michel, 1975.

DE MAN, Paul. Allégorie de la lecture [1979]. Trad. de Thomas Trézise. Paris: Galilée, 1989.

DERRIDA, Jacques. L'Écriture et la différence. Paris: Seuil [1967] (collection Points), 1979.

DICHY, Albert. L’Ennemi déclaré, textes et entretiens [1964-1985]. Paris: Gallimard, 1991.

DICHY, Albert; FOUCHÉ, Pascal. Jean Genet. Matricule 192.102. Chronique des années 1910-1944. Paris: Gallimard (collection NRF), 2010.

GENET, Jean. Un Captif amoureux, Paris: Gallimard (collection Blanche), 1986. . Um cativo apaixonado. Trad. C. Fares. São Paulo: Arx, 2003.

MALLARMÉ, Stephen. Igitur, Divagations, Un coup de dés. Paris: Gallimard, 1976 (édition de poche).

MOUSSARON, Jean-Pierre (org.). Grand Cahier Michel Deguy. Bordeaux: Editions Le bleu du ciel, 2007. 